\title{
Optimized outcome prediction in breast cancer by combining the 70-gene signature with clinical risk prediction algorithms
}

\author{
C. A. Drukker $\cdot$ M. V. Nijenhuis $\cdot$ J. M. Bueno-de-Mesquita $\cdot$ \\ V. P. Retèl · W. H. van Harten $\cdot$ H. van Tinteren $\cdot$ J. Wesseling $\cdot$ \\ M. K. Schmidt • L. J. van't Veer · G. S. Sonke • E. J. T. Rutgers • \\ M. J. van de Vijver $\cdot$ S. C. Linn
}

Received: 18 November 2013/Accepted: 3 April 2014/Published online: 24 April 2014

(C) The Author(s) 2014. This article is published with open access at Springerlink.com

\begin{abstract}
Clinical guidelines for breast cancer treatment differ in their selection of patients at a high risk of recurrence who are eligible to receive adjuvant systemic treatment (AST). The 70-gene signature is a molecular tool to better guide AST decisions. The aim of this study was to evaluate whether adding the 70 -gene signature to clinical risk prediction algorithms can optimize outcome prediction and consequently treatment decisions in early stage, nodenegative breast cancer patients. A 70-gene signature was available for 427 patients participating in the RASTER study (cT1-3N0M0). Median follow-up was 61.6 months. Based on 5-year distant-recurrence free interval (DRFI) probabilities survival areas under the curve (AUC) were calculated and compared for risk estimations based on the
\end{abstract}

Electronic supplementary material The online version of this article (doi:10.1007/s10549-014-2954-2) contains supplementary material, which is available to authorized users.

C. A. Drukker · M. V. Nijenhuis - E. J. T. Rutgers

Department of Surgical Oncology, Netherlands Cancer Institute,

Postbus 90203, 1006 BE Amsterdam, The Netherlands

J. M. Bueno-de-Mesquita · J. Wesseling · M. J. van de Vijver Department of Pathology, Netherlands Cancer Institute,

Postbus 90203, 1006 BE Amsterdam, The Netherlands

V. P. Retèl · W. H. van Harten · M. K. Schmidt

Division of Psychosocial Research and Epidemiology,

Netherlands Cancer Institute, Postbus 90203,

1006 BE Amsterdam, The Netherlands

H. van Tinteren

Department of Biometrics, Netherlands Cancer Institute,

Postbus 90203, 1006 BE Amsterdam, The Netherlands

M. K. Schmidt · L. J. van't Veer

Department of Molecular Pathology, Netherlands Cancer

Institute, Postbus 90203, 1006 BE Amsterdam, The Netherlands six clinical risk prediction algorithms: Adjuvant! Online (AOL), Nottingham Prognostic Index (NPI), St. Gallen (2003), the Dutch National guidelines (CBO 2004 and NABON 2012), and PREDICT plus. Also, survival AUC were calculated after adding the 70-gene signature to these clinical risk estimations. Systemically untreated patients with a high clinical risk estimation but a low risk 70-gene signature had an excellent 5-year DRFI varying between 97.1 and $100 \%$, depending on the clinical risk prediction algorithms used in the comparison. The best risk estimation was obtained in this cohort by adding the 70-gene signature to CBO 2012 (AUC: 0.644) and PREDICT (AUC: 0.662). Clinical risk estimations by all clinical algorithms improved by adding the 70 -gene signature. Patients with a low risk 70-gene signature have an excellent survival, independent of their clinical risk estimation. Adding the 70-gene signature to clinical risk prediction algorithms

\author{
L. J. van't Veer \\ Agendia Inc., Amsterdam, The Netherlands \\ L. J. van't Veer \\ Helen Diller Family Comprehensive Cancer Center, USCF, \\ Box 0808, San Francisco, CA 94143-0808, USA \\ G. S. Sonke · S. C. Linn $(\square)$ \\ Department of Medical Oncology, Netherlands Cancer Institute, \\ Postbus 90203, 1006 BE Amsterdam, The Netherlands \\ e-mail: s.linn@nki.nl \\ M. J. van de Vijver \\ Department of Pathology, Academic Medical Center \\ Amsterdam, Meibergdreef 9, 1105 AZ Amsterdam, \\ The Netherlands \\ S. C. Linn \\ Department of Pathology, University Medical Center Utrecht, \\ Postbus 95500, 3508 GA Utrecht, The Netherlands
}


improves risk estimations and therefore might improve the identification of early stage node-negative breast cancer patients for whom AST has limited value. In this cohort, the PREDICT plus tool in combination with the 70-gene signature provided the best risk prediction.

Keywords Breast cancer - 70-Gene signature . Prognosis prediction - Adjuvant systemic treatment . Clinical guidelines

\section{Introduction}

For the past decade, the selection of early stage breast cancer patients who are at a high risk of recurrence and eligible to receive adjuvant systemic treatment (AST) is based on clinicopathological factors, such as age, tumor size, nodal status, histological grade, and hormone-receptor status. Several clinical risk prediction algorithms used in online tools and guidelines, such as Adjuvant! Online (AOL), the Nottingham Prognostic Index (NPI), the St. Gallen expert panel recommendations of 2003, and the Dutch national guidelines of 2004 and 2012, use these factors in specific algorithms for risk estimations and AST recommendations [1-6]. A relatively new online tool for outcome prediction in breast cancer patients is PREDICT plus [7]. This tool not only uses the clinicopathological factors mentioned above, but also incorporates human epidermal growth factor receptor 2 (HER2) status and method of detection. Both of these factors have proven to be independent prognostic factors in overall and breast cancer-specific survival $[7,8]$.

Even with the aid of these clinical risk prediction algorithms, individual risk assessment remains challenging. Each of these clinical risk prediction algorithms may define a slightly different group of patients at a low or high risk, which are partly non-overlapping. This indicates that it is unclear which tool or guideline has the highest prognostic accuracy for the individual patient [1, 5, 6, 9]. Moreover, online tools such as AOL provide a survival probability without stratification into high versus low risk. The choice for a specific cut-off point in risk clearly influences the concordance with other tools [10]. Gene-expression classifiers have been developed and validated on historic data to refine clinical risk estimations and related AST recommendations [11, 12]. One of these classifiers is the 70-gene signature (MammaPrint ${ }^{\mathrm{TM}}$, Agendia Inc., Amsterdam, the Netherlands) [13, 14]. Between 2004 and 2006, the 70-gene signature has been assessed in the first prospective study using a gene-expression classifier as a risk estimation tool in addition to clinicopathological factors to determine the need for AST. A considerable discrepancy in risk estimations among different clinical guidelines and the 70-gene signature was observed $[9,15]$. Recently, the 5-year follow-up data of the RASTER study were reported showing an excellent distant-recurrence free interval (DRFI) of $97 \%$ for patients with a low risk 70-gene signature. Patients with a high risk 70-gene signature showed a DRFI of $92 \%$ [16]. When compared to AOL, 70-gene signature low-AOL high risk patients who did not receive any AST showed a DRFI of $100 \%$. This indicates that omission of chemotherapy in these patients may not compromise outcome. Up to the evaluated 5-year median survival, the number of events is small and the follow-up time is relatively short. However, AOL is not the only risk estimation tool used in clinical practice today. In addition, the 70-gene signature is more likely to be added to clinical risk prediction algorithms instead of replacing them. Therefore, we evaluated whether adding the 70 -gene signature to clinical risk prediction algorithms can improve individual outcome prediction in early stage, node-negative breast cancer patients.

\section{Patients and methods}

The RASTER study design, patient eligibility criteria, and study logistics have been described elsewhere (www.con trolled-trials.com/ISRCTN71917916) [15]. In short, 812 female patients were enrolled in 16 hospitals in the Netherlands. 427 patients were postoperatively eligible and for them a 70-gene signature (MammaPrint ${ }^{\mathrm{TM}}$, Agendia Inc.) was obtained. All patients were between 18 and 61 years old and had a histologically confirmed unilateral, unifocal, primary operable, invasive adenocarcinoma of the breast (cT1-3N0M0). All patients were primarily surgically treated with either breast-conserving surgery or mastectomy. To insure routine clinical practice, the initial histopathology data were used for clinical risk assessment by the treating physician and in the statistical analysis, without central review of the paraffin-embedded tumor samples. Details on tumor grading, assessment of hormone-receptor status and HER2 status, RNA extraction and microarray analysis have been described elsewhere [15]. Decisions on whether or not to treat with AST (comprising chemotherapy and/or endocrine therapy) in the RASTER study were based on the Dutch national guidelines of 2004, the 70-gene signature, and doctors' and patients' preferences [15]. More detailed insight on the follow-up data of this cohort is described elsewhere [16].

\section{Clinical risk prediction algorithms}

Hereafter, risk assessment by use of clinicopathological factors is referred to as "clinical risk." Guidelines used in this study to assess clinical risk were Adjuvant! Online (AOL), Nottingham Prognostic Index (NPI), the St. Gallen expert panel recommendations (2003, current at the time the 
Table 1 Survival AUC and proportions of low risk for clinicopathological guidelines and in combination with the 70-gene signature

\begin{tabular}{|c|c|c|c|c|c|}
\hline & Low risk guideline & $\begin{array}{l}\text { c-index guideline } \\
(95 \% \mathrm{CI})\end{array}$ & Low risk 70 -gene signature & $\begin{array}{l}\text { c-index guideline } \\
+70 \text {-gene signature }\end{array}$ & $p$ value \\
\hline $\mathrm{AOL}$ & $132(30.9 \%)$ & $0.532(0.416-0.649)$ & $219(51.3 \%)$ & $0.619(0.491-0.748)$ & 0.03 \\
\hline NPI & $248(58.1 \%)$ & $0.591(0.454-0.728)$ & $219(51.3 \%)$ & $0.638(0.524-0.752)$ & 0.05 \\
\hline St. Gallen & $73(17.1 \%)$ & $0.552(0.465-0.64)$ & $219(51.3 \%)$ & $0.631(0.52-0.742)$ & 0.05 \\
\hline Dutch national guidelines 2004 & $243(56.9 \%)$ & $0.586(0.449-0.724)$ & $219(51.3 \%)$ & $0.639(0.512-0.765)$ & 0.04 \\
\hline Dutch national guidelines 2012 & $124(29.0 \%)$ & $0.581(0.477-0.685)$ & $219(51.3 \%)$ & $0.644(0.502-0.786)$ & 0.05 \\
\hline PREDICT plus & $228(53.4 \%)$ & $0.627(0.538-0.717)$ & $219(51.3 \%)$ & $0.662(0.537-0.786)$ & 0.27 \\
\hline
\end{tabular}

Bold-proportion of low risk increased with the 70-gene signature. Italics-proportion of low risk decreased with the 70-gene signature

RASTER study was conducted), the Dutch national guidelines (2004, current at the time the RASTER study was conducted, and 2012), and PREDICT plus. Adjuvant! Online software, version 8.0, calculates the 10 -year survival probabilities based on the age of the patient, tumor size, tumor grade, estrogen receptor (ER) status, and nodal status [5, 10]. Patients were considered high risk if their calculated 10-year survival probability was less than $90 \%$ [15]. This cut off was also used in the RASTER study and similar to the cut off used in the MINDACT trial. The NPI computes a score with the algorithm: $0.2 \times$ size $(\mathrm{cm})+$ grade + nodal status. A moderate or high risk was defined as a score greater than 3.4 $[1,17]$. The St. Gallen expert panel of 2003 recommended to define low clinical risk as ER positive or progesterone receptor (PR)-positive status (or both) and all the following criteria: tumor size of $2 \mathrm{~cm}$ or smaller, grade 1, and age 35 years or over. All other tumors were deemed to be associated with a moderate or high risk of distant metastasis and death [2]. The 2004 Dutch national guidelines define high clinical risk for node-negative breast cancer as age 35 years or younger (except for tumors grade 1 of $10 \mathrm{~mm}$ or smaller), a tumor of grade 3 and $10 \mathrm{~mm}$ or larger, or grade 2 and $20 \mathrm{~mm}$ or larger, and every tumor larger than $30 \mathrm{~mm}$. Adjuvant endocrine treatment was advised only in clinically high risk patients with hormone-receptor-positive tumors in combination with chemotherapy [10]. AST was justified for patients with a 10-year survival probability of less than $80 \%$. The less restrictive Dutch guidelines of 2012 define high clinical risk for node-negative breast cancer as age under 35 years except for tumors grade 1 of $10 \mathrm{~mm}$ or smaller, or age 35 years or older with a tumor of grade 2 or higher, and 10-20 $\mathrm{mm}$ in size, and every tumor larger than $20 \mathrm{~mm}$. According to this 2012 guideline, AST was justified for patients with a 10-year survival probability of less than $85 \%$. The online PREDICT plus tool estimates the 5- and 10-year survival probabilities based on the age of the patient, method of detection, tumor size, tumor grade, number of positive nodes, ER and HER2 status [7]. We defined a 5-year survival probability of $<95 \%$, which is in line with the cut offs used for Adjuvant! Online. All clinicopathological factors used by the guidelines mentioned above were summarized elsewhere [18]. In our analyses, a moderate or high clinical risk was considered an indication for AST.

Statistical analysis

We estimated a 5-year DRFI, comprising distant recurrence and death from breast cancer [19]. Survival curves were constructed using the Kaplan-Meier method and compared using the log-rank test. Survival ROC and AUC (c-index) analyses were performed to evaluate the additional value of the 70-gene signature to the clinical guidelines described in this manuscript. An ANOVA test was used to compare the model before and after adding the 70-gene signature. A significant finding was defined as a $p$ value below 0.05 . Analyses were performed using SAS version 9.2 and R version 2.14.0.

\section{Results}

Patient and tumor characteristics, AST and outcome stratified by 70 -gene signature

Patient and tumor characteristics were described elsewhere [15]. After a median follow-up time of 61.6 months, 24 DRFI events occurred. Eleven patients died of whom nine due to breast cancer. The 5-year DRFI probabilities for 70 -gene signature low risk $(n=219)$ and high risk $(n=208)$ patients were $97.0 \%$ (95\% CI 94.7-99.4) and $91.7 \% \quad(95 \%$ CI $87.9-95.7) \quad(p=0.03)$, respectively (Supplementary Fig. 1) [16].

Additional value of 70 -gene signature to clinical risk assessment

Adding the 70-gene signature to clinical risk prediction algorithms improved outcome prediction. For most guidelines, this was a borderline significant improvement of the c-index (Table 1). The c-index was highest for PREDICT plus (0.627), followed by NPI (0.591), and the Dutch national guidelines of 2004 (0.586). Adding the 70-gene signature improved the model to 0.638 for NPI $(p=0.05)$ 
Table 2 Distribution of patients $(n=427)$ over the four risk categories defined by 70-gene signature and clinical risk and proportion and type of AST received per category
AST Adjuvant systemic therapy, $C T$ adjuvant chemotherapy, $E T$ adjuvant endocrine therapy

\begin{tabular}{|c|c|c|c|c|c|}
\hline 70-Gene signature & AOL & No AST & $\mathrm{CT}$ & ET & $\mathrm{ET}+\mathrm{CT}$ \\
\hline Low & Low & $88 / 95(93 \%)$ & $0 / 95(0 \%)$ & $4 / 95(4 \%)$ & 3/95 (3\%) \\
\hline High & Low & $5 / 37(14 \%)$ & $3 / 37(8 \%)$ & $11 / 37(30 \%)$ & $18 / 37(49 \%)$ \\
\hline Low & High & $70 / 124(56 \%)$ & $1 / 124(1 \%)$ & 24/124 (19\%) & $29 / 124(23 \%)$ \\
\hline High & High & $5 / 171(3 \%)$ & 73/171 (43\%) & 18/171 (11\%) & 75/171 (44\%) \\
\hline 70-Gene signature & NPI & No AST & CT & ET & $\mathrm{ET}+\mathrm{CT}$ \\
\hline Low & Low & $153 / 175(87 \%)$ & $0 / 175(0 \%)$ & $14 / 175(8 \%)$ & $8 / 175(5 \%)$ \\
\hline High & Low & $7 / 73(10 \%)$ & $7 / 73(10 \%)$ & $23 / 73(32 \%)$ & $36 / 73(49 \%)$ \\
\hline Low & High & $5 / 44(11 \%)$ & $1 / 44(2 \%)$ & $14 / 44(32 \%)$ & $24 / 44(55 \%)$ \\
\hline High & High & $3 / 135(2 \%)$ & $69 / 135(51 \%)$ & $6 / 135(4 \%)$ & $57 / 135(42 \%)$ \\
\hline 70-Gene signature & St. Gallen & No AST & $\mathrm{CT}$ & ET & $\mathrm{ET}+\mathrm{CT}$ \\
\hline Low & Low & $59 / 62(95 \%)$ & $0 / 62(0 \%)$ & $3 / 62(5 \%)$ & $0 / 62(0 \%)$ \\
\hline High & Low & $2 / 11(18 \%)$ & $0 / 11(0 \%)$ & $5 / 11(45 \%)$ & $4 / 11(36 \%)$ \\
\hline Low & High & $99 / 157(63 \%)$ & $1 / 157(1 \%)$ & $25 / 157(16 \%)$ & $32 / 157(20 \%)$ \\
\hline High & High & $8 / 196(4 \%)$ & 76/196 (39 \%) & $23 / 196(12 \%)$ & $89 / 196(45 \%)$ \\
\hline 70-Gene signature & $\begin{array}{l}\text { Dutch national } \\
\text { guidelines } 2004\end{array}$ & No AST & $\mathrm{CT}$ & ET & $\mathrm{ET}+\mathrm{CT}$ \\
\hline Low & Low & $152 / 167(91 \%)$ & $0 / 167(0 \%)$ & 13/167 (8 \%) & $2 / 167(1 \%)$ \\
\hline High & Low & $8 / 76(11 \%)$ & $10 / 76(13 \%)$ & $25 / 76(33 \%)$ & $33 / 76(43 \%)$ \\
\hline Low & High & $6 / 52(12 \%)$ & $1 / 52(2 \%)$ & $15 / 52(29 \%)$ & $30 / 52(58 \%)$ \\
\hline High & High & $2 / 132(2 \%)$ & $66 / 132(50 \%)$ & 4/132(3\%) & $60 / 132(45 \%)$ \\
\hline 70-Gene signature & $\begin{array}{l}\text { Dutch national } \\
\text { guidelines } 2012\end{array}$ & No AST & $\mathrm{CT}$ & ET & $\mathrm{ET}+\mathrm{CT}$ \\
\hline Low & Low & $83 / 88(94 \%)$ & $0 / 88(0 \%)$ & $5 / 88(6 \%)$ & $0 / 88(0 \%)$ \\
\hline High & Low & $4 / 36(11 \%)$ & $6 / 36(17 \%)$ & $14 / 36(39 \%)$ & $12 / 36(33 \%)$ \\
\hline Low & High & $75 / 131(57 \%)$ & $1 / 131(1 \%)$ & 23/131 (18 \%) & $32 / 131(24 \%)$ \\
\hline High & High & $6 / 172(3 \%)$ & $70 / 172(41 \%)$ & $15 / 172(9 \%)$ & $81 / 172(47 \%)$ \\
\hline $\begin{array}{l}\text { 70-Gene } \\
\text { signature }\end{array}$ & PREDICT plus & No AST & $\mathrm{CT}$ & ET & $\mathrm{ET}+\mathrm{CT}$ \\
\hline Low & Low & $141 / 170(83 \%)$ & $0 / 170(0 \%)$ & $16 / 170(9 \%)$ & 13/170 (8 \%) \\
\hline High & Low & $3 / 58(5 \%)$ & $1 / 58(2 \%)$ & $22 / 58(38 \%)$ & $32 / 58(55 \%)$ \\
\hline Low & High & $17 / 49(35 \%)$ & $1 / 49(2 \%)$ & $12 / 49(25 \%)$ & $19 / 49(39 \%)$ \\
\hline High & High & $7 / 150(5 \%)$ & $75 / 150(50 \%)$ & $7 / 150(5 \%)$ & $61 / 150(41 \%)$ \\
\hline
\end{tabular}

and to 0.639 for the Dutch national guidelines of 2004 $(p=0.04)$. The best risk predictions were achieved when using PREDICT plus (0.662) or the Dutch guidelines of 2012 (0.644) in combination with the 70-gene signature. The c-index for AOL was lowest, before (0.532) and after adding the 70 -gene signature (0.619).

Discordance between clinical risk assessment and the 70-gene signature

Discordant risk estimations occurred in $37 \%$ of the cases (161/427) for AOL, $27 \%$ for NPI (117/427), $39 \%$ for St.
Gallen (168/427), $30 \%$ for the Dutch national guidelines of 2004 (128/427), $39 \%$ for the guidelines of 2012 (167/ 427), and $25 \%$ for PREDICT plus (107/427) (Table 2; Fig. 1). Most discordant cases were 70-gene signature low risk and clinically high risk; $29 \%$ for AOL (124/427), $10 \%$ for NPI (44/427), $37 \%$ for St. Gallen (157/427), $12 \%$ for the Dutch national guidelines of 2004 (52/427), $31 \%$ for the guidelines of $2012(131 / 427)$, and $11 \%$ for PREDICT plus at 5 years (49/427).

Table 2 summarizes the AST given in the different categories stratified by 70 -gene signature and clinical risk. When the 70-gene signature was used, $20 \%$ less patients 


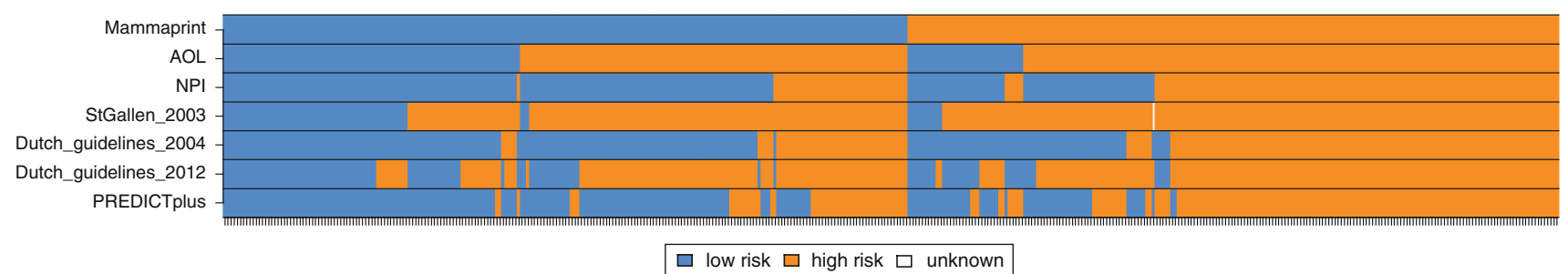

Fig. 1 Risk estimations per case stratified by clinical risk prediction algorithms and the 70-gene signature. Cases were ordered according to their 70-gene signature

would be eligible to receive ACT compared to AOL, $34 \%$ less compared to St. Gallen, $6 \%$ less compared to the Dutch guidelines of 2004, and $22 \%$ less compared to the guidelines of 2012. The 70-gene signature identifies $7 \%$ more patients eligible to receive ACT compared to NPI and $2 \%$ more compared to PREDICT plus.

The 5-year DRFI probabilities for AOL low risk $(n=132)$ and high risk $(n=295)$ patients were $96.7 \%$ (95\% CI 93.5-100) and 93.4\% (95\% CI 90.4-96.4), respectively $(p=0.24)$. For NPI low risk $(n=248)$ and high risk $(n=179)$ patients, the 5-year DRFI probabilities were $96.7 \%$ (95\% CI 94.2-99.2) and 91.3\% (95\% CI 87.2-95.6) $(p=0.03)$. The St. Gallen low risk $(n=73)$ and high risk $(n=353)$ patients showed 5-year DRFI probabilities of $98.5 \%$ (95\% CI 95.7-100) and $93.5 \%$ (95\% CI 90.9-96.3) ( $p=0.08)$. For the Dutch national guidelines of 2004 low risk $(n=243)$ and high risk $(n=184)$ patients, the 5-year DRFI probabilities were $96.6 \% \quad(95 \%$ CI $94.2-99.2)$ and $91.5 \% \quad(95 \%$ CI 87.4-95.7), respectively ( $p=0.11$ ), while for the Dutch national guidelines of 2012 low risk $(n=124)$ and high risk $(n=303)$ patients the 5-year DRFI probabilities were $99.2 \% \quad(95 \%$ CI $97.6-100)$ and $92.4 \% \quad(95 \%$ CI 89.3-95.6) ( $p=0.02)$. The 5-year prediction of PREDICT plus low risk $(n=228)$ and high risk $(n=199)$ patients showed 5-year DRFI probabilities of $96.8 \%(95 \% \mathrm{CI}$ 94.2-99.4) and 91.7\% (95\% CI 87.9-95.7), respectively $(p=0.004)$ (Fig. 2). Table 3 summarizes DRFI probabilities according to the combined risk categories.

Subgroup analyses of therapy-naïve patients

Of the patients who had a low risk 70-gene signature $85 \%$ did not receive adjuvant chemotherapy. Only $27 \%$ of the 70-gene signature low risk patients received adjuvant endocrine therapy. Among the low risk systemically untreated patients, no significant difference was seen for most clinical risk algorithms $(p=0.29$ for AOL, $p=0.66$ for NPI, $p=0.37$ for St. Gallen, $p=0.65$ for the 2004, and $p=0.14$ for the 2012 Dutch national guidelines) between patients with a concordant low risk assessment and patients with a 70-gene signature low risk result but a high risk assessment by one or more of the clinical indexes (Fig. 1).
Only the PREDICT plus tool shows that patients with a concordant low risk assessment $(n=141)$ at 5 years have a significantly better DRFI survival probability compared to patients with a low risk 70-gene signature and a high risk according to PREDICT plus $(n=17)(p=0.002)$.

\section{Discussion}

The RASTER study was the first study to prospectively evaluate the outcome of patients for whom the 70-gene signature was used for risk estimations and AST recommendations. The recently published 5-year follow-up data of this study provide the opportunity to evaluate the additional value of a gene-expression classifier to risk estimations based on clinicopathological factors incorporated in clinical tools and guidelines. Of all clinical risk prediction algorithms used in this study, the online PREDICT plus tool provided the best risk estimation. Addition of the 70-gene signature to either the PREDICT plus tool or the Dutch national guidelines of 2012 resulted in the best risk estimations in this cohort. Interestingly, AOL showed the lowest c-index before and after adding the 70-gene signature. This might be explained by the fact that this guideline does not incorporate HER2 status, while the Dutch guidelines of 2012 and PREDICT plus do take this clinicopathological factor into account. In addition, as AOL does not provide a classification into high versus low risk, the choice for a specific cut-off point may influence these results. Previous analyses already showed that method of detection is an independent prognostic factor in breast cancer-specific and overall survival. The fact that the PREDICT plus tool takes the method of detection into account may explain why this risk prediction algorithm performs so well in this cohort. When solely using the 70-gene signature, the number of patients at high risk of recurrence who are eligible for adjuvant chemotherapy would be reduced by $20 \%$ compared to AOL. As a similar comparison was made in the MINDACT trial (AOL in MINDACT does include HER2), one can hypothesize that a similar reduction in chemotherapy will be seen in this large, randomized controlled phase 3 trial. Analyses of the 

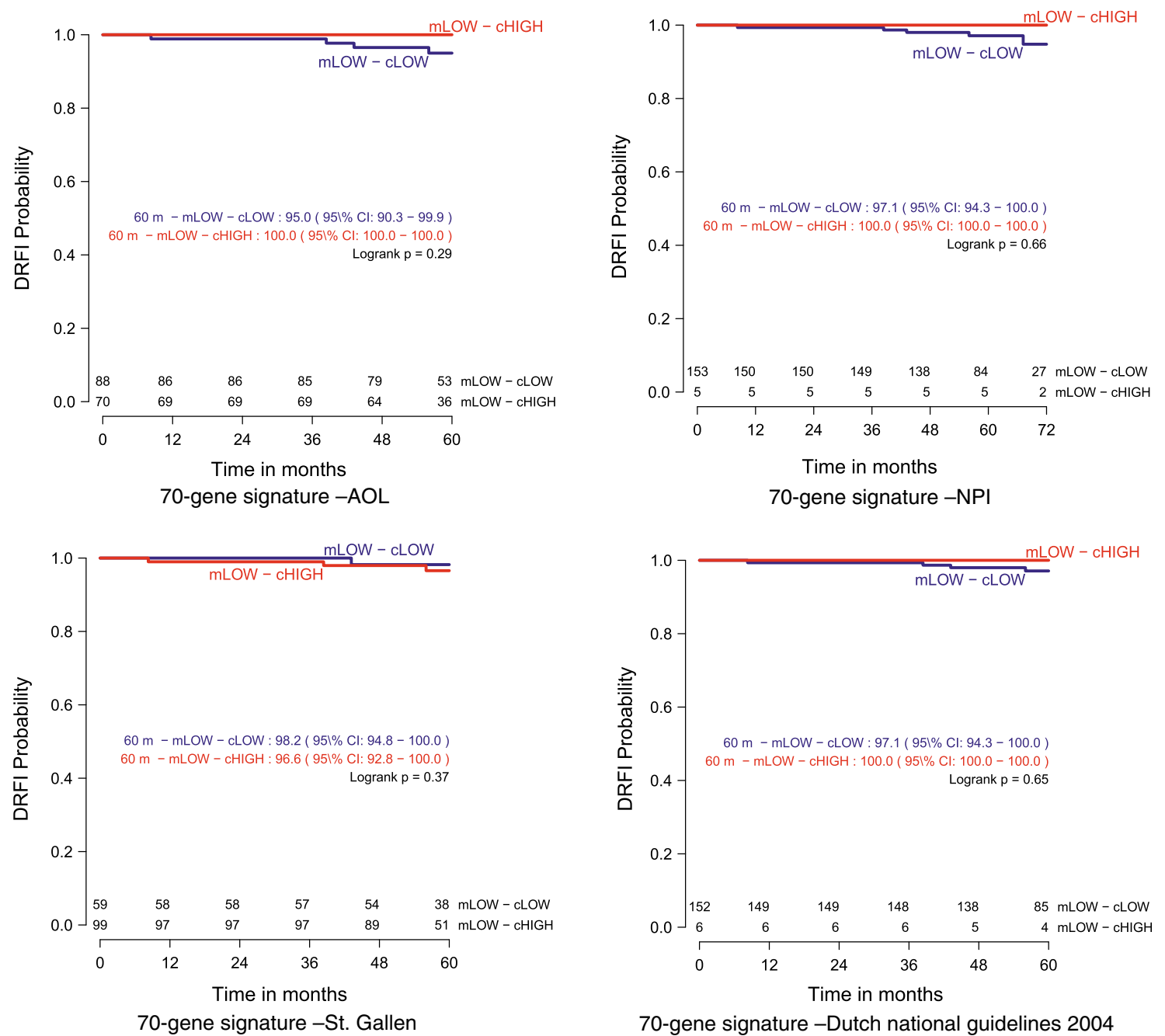

70-gene signature -Dutch national guidelines 2004
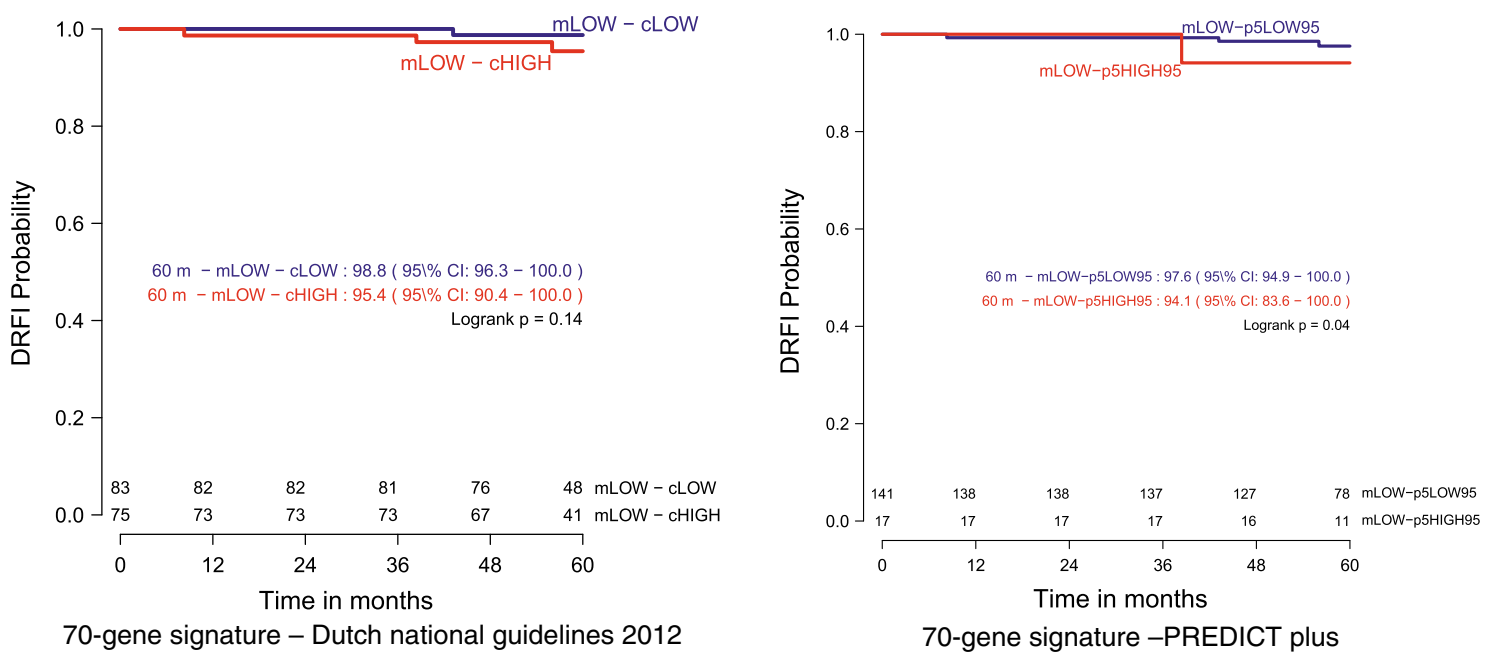

Fig. 2 5-year outcome of systemic therapy-naïve patients with a low risk 70-gene signature

first 800 patients included in the MINDACT trial show a similar possible reduction in adjuvant chemotherapy of $18 \%(141 / 800)$. Overall, the 5-year outcome of this cohort of patients for whom the 70-gene signature result was prospectively used to guide AST decisions was favorable. One should take into consideration that a substantial 
Table 3 Kaplan-Meier risk estimations for DRFI and DDFS according to 70 -gene signature and clinical risk stratification
ACT Adjuvant chemotherapy, $D R F I$ Distant-recurrence free interval, $D D F S$ distant disease free survival

\begin{tabular}{|c|c|c|c|}
\hline 70-Gene signature & $\mathrm{AOL}$ & ACT & 5-year DRFI $(\%)(95 \% \mathrm{CI})$ \\
\hline Low & Low & $3 / 95(3 \%)$ & $95.3(90.9-100)$ \\
\hline High & Low & $21 / 37(57 \%)$ & $100(100-100)$ \\
\hline Low & High & $30 / 124(24 \%)$ & $98.4(96.1-100)$ \\
\hline High & High & $148 / 171(87 \%)$ & $89.8(85.1-94.8)$ \\
\hline 70-Gene signature & NPI & ACT & 5-year DRFI $(\%)(95 \% \mathrm{CI})$ \\
\hline Low & Low & $8 / 175(5 \%)$ & $97.4(95.0-100)$ \\
\hline High & Low & $43 / 73(59 \%)$ & $95.3(90.1-100)$ \\
\hline Low & High & $25 / 44(57 \%)$ & $95.5(89.5-100)$ \\
\hline High & High & $126 / 135(93 \%)$ & $89.9(84.9-95.3)$ \\
\hline 70-Gene signature & St. Gallen & ACT & 5-year DRFI $(\%)(95 \% \mathrm{CI})$ \\
\hline Low & Low & $0 / 62(0 \%)$ & $98.3(95.0-100)$ \\
\hline High & Low & $4 / 11(36 \%)$ & $100(100-100)$ \\
\hline Low & High & $33 / 157(21 \%)$ & $96.5(93.5-99.6)$ \\
\hline High & High & $165 / 196(84 \%)$ & $91.2(87.1-95.5)$ \\
\hline 70-Gene signature & $\begin{array}{l}\text { Dutch national } \\
\text { guidelines } 2004\end{array}$ & ACT & 5-year DRFI $(\%)(95 \% \mathrm{CI})$ \\
\hline Low & Low & $2 / 167(1 \%)$ & $97.3(94.8-100)$ \\
\hline High & Low & $43 / 76(57 \%)$ & $95.5(90.6-100)$ \\
\hline Low & High & $31 / 52(60 \%)$ & $96.2(91.1-100)$ \\
\hline High & High & $126 / 132(95 \%)$ & $89.7(84.5-95.2)$ \\
\hline 70-Gene signature & $\begin{array}{l}\text { Dutch national } \\
\text { guidelines } 2012\end{array}$ & ACT & 5-year DRFI $(\%)(95 \% \mathrm{CI})$ \\
\hline Low & Low & $0 / 88(0 \%)$ & $98.8(96.5-100)$ \\
\hline High & Low & $18 / 36(50 \%)$ & $100(100-100)$ \\
\hline Low & High & $33 / 131(25 \%)$ & $95.8(92.3-99.5)$ \\
\hline High & High & $151 / 172(88 \%)$ & $89.8(85.2-94.8)$ \\
\hline 70-Gene signature & PREDICT plus & ACT & 5-year DRFI $(\%)(95 \% \mathrm{CI})$ \\
\hline Low & Low & $13 / 170(8 \%)$ & $98.0(95.7-100)$ \\
\hline High & Low & $33 / 58(57 \%)$ & $93.9(87.5-100)$ \\
\hline Low & High & $20 / 49(41 \%)$ & $93.9(87.4-100)$ \\
\hline High & High & $136 / 150(91 \%)$ & $91.0(86.5-95.8)$ \\
\hline
\end{tabular}

conclusions. A larger cohort is necessary to evaluate the additional prognostic value of the 70-gene signature to PREDICT plus tool. An advantage, but also a limitation of this study is that the actual treatment decisions were based on the Dutch guidelines of 2004, the 70-gene signature result and preferences of doctors and patients. The study design provides an optimal reflection of daily clinical practice, but subtle selection mechanisms may be present and may have influenced our results. Another possible limitation is that all clinical tools and guidelines included in our analyses use slightly different definitions of high and low risk. These differences create an additional group of patients for whom the guidelines provide discordant risk estimations. Also, some guidelines base their risk
PREDICT plus tool. However, in this subgroup the number of patients $(n=17)$ was too low to draw any firm 
assessment on 5-year survival probabilities, while others on 10-year survival probabilities. In our analyses, we were unable to adjust for these differences which make a headto-head comparison more difficult to interpret. Still, the guidelines as used in this study reflect the way they are used in current daily clinical practice. The c-indexes reported here leave room for improvement and this again underlines the need for more accurate, personalized breast cancer care. Also, it should be kept in mind that the results of this study are based on a case mix of relatively young ( $<61$ years) breast cancer patients. Finally, central pathology revision might have changed the results, since an earlier report showed that for $8 \%$ of the patients AOL risk estimations would change based on revised pathology [20].

In conclusion, our results indicate that adding the 70-gene signature clinical guidelines with the 70-gene signature improves risk estimations and therefore may help to identify early stage node-negative breast cancer patients for whom limited AST might be appropriate and for whom overtreatment can be avoided. In this cohort, PREDICT plus appeared to be a promising tool to identify patients for whom limited AST in case of early stage node-negative disease might be appropriate.

Acknowledgments We are indebted to the women who participated in the RASTER study; to the doctors, nurses, and data managers from the participating hospitals in the Netherlands that enrolled patients in the RASTER-study and contributed to the collection of follow-up data.

Conflict of interest The RASTER study was financially supported by the Dutch Health Care Insurance Board (CVZ). LJvV and MJvdV are named inventors on the patent for the 70-gene signature used in this study. LJvV reports being shareholder in and part-time employed by Agendia Inc., the commercial company that markets the 70 -gene signature as MammaPrint ${ }^{\mathrm{TM}}$. LJVV was supported by the Dutch Genomics Initiative "Cancer Genomics Centre."

Open Access This article is distributed under the terms of the Creative Commons Attribution Noncommercial License which permits any noncommercial use, distribution, and reproduction in any medium, provided the original author(s) and the source are credited.

\section{References}

1. D'Eredita' G, Giardina C, Martellotta M, Natale T, Ferrarese F (2001) Prognostic factors in breast cancer: the predictive value of the Nottingham Prognostic Index in patients with a long-term follow-up that were treated in a single institution. Eur J Cancer 37:591-596

2. Goldhirsch A, Glick JH, Gelber RD, Coates AS, Senn HJ (2001) Meeting highlights: International Consensus Panel on the treatment of primary breast cancer. Seventh international conference on adjuvant therapy of primary breast cancer. J Clin Oncol 19:3817-3827

3. Integraal Kankercentrum Nederland: NABON richtlijn mammacarcinoom (2012)

4. Kwaliteitsinstituut voor de Gezondheidszorg CBO VvlK: Adjuvante Systemische Therapie voor het Operabel Mammacarcinoom (2004) Richtlijn Behandeling van het Mammacarcinoom 46-70
5. Olivotto IA, Bajdik CD, Ravdin PM, Speers CH, Coldman AJ, Norris BD, Davis GJ, Chia SK, Gelmon KA (2005) Populationbased validation of the prognostic model ADJUVANT! for early breast cancer. J Clin Oncol 23:2716-2725

6. Goldhirsch A, Wood WC, Gelber RD, Coates AS, Thurlimann B, Senn HJ (2003) Meeting highlights: updated international expert consensus on the primary therapy of early breast cancer. J Clin Oncol 21:3357-3365

7. Wishart GC, Bajdik CD, Dicks E, Provenzano E, Schmidt MK, Sherman M, Greenberg DC, Green AR, Gelmon KA, Kosma VM, Olson JE, Beckmann MW, Winqvist R, Cross SS, Severi G, Huntsman D, Pylkas K, Ellis I, Nielsen TO, Giles G, Blomqvist C, Fasching PA, Couch FJ, Rakha E, Foulkes WD, Blows FM, Begin LR, van't Veer LJ, Southey M, Nevanlinna H, Mannermaa A, Cox A, Cheang M, Baglietto L, Caldas C, Garcia-Closas M, Pharoah PD (2012) PREDICT plus: development and validation of a prognostic model for early breast cancer that includes HER2. Br J Cancer 107:800-807

8. Mook S, van't Veer LJ, Rutgers EJ, Ravdin PM, van de Velde AO, van Leeuwen FE, Visser O, Schmidt MK (2011) Independent prognostic value of screen detection in invasive breast cancer. J Natl Cancer Inst 103:585-597

9. Bueno-de-Mesquita JM, Sonke GS, van de Vijver MJ, Linn SC (2011) Additional value and potential use of the 70-gene prognosis signature in node-negative breast cancer in daily clinical practice. Ann Oncol 22:2021-2030

10. Ravdin PM, Siminoff LA, Davis GJ, Mercer MB, Hewlett J, Gerson N, Parker HL (2001) Computer program to assist in making decisions about adjuvant therapy for women with early breast cancer. J Clin Oncol 19:980-991

11. Buyse M, Loi S, van't Veer L, Viale G, Delorenzi M, Glas AM, d'Assignies MS, Bergh J, Lidereau R, Ellis P, Harris A, Bogaerts J, Therasse P, Floore A, Amakrane M, Piette F, Rutgers E, Sotiriou C, Cardoso F, Piccart MJ (2006) Validation and clinical utility of a 70-gene prognostic signature for women with nodenegative breast cancer. J Natl Cancer Inst 98:1183-1192

12. Ross JS, Hatzis C, Symmans WF, Pusztai L, Hortobagyi GN (2008) Commercialized multigene predictors of clinical outcome for breast cancer. Oncologist 13:477-493

13. van't Veer LJ, Dai H, van de Vijver MJ, He YD, Hart AA, Mao M, Peterse HL, van der Kooy K, Marton MJ, Witteveen AT, Schreiber GJ, Kerkhoven RM, Roberts C, Linsley PS, Bernards R, Friend SH (2002) Gene expression profiling predicts clinical outcome of breast cancer. Nature 415:530-536

14. van de Vijver MJ, He YD, van't Veer LJ, Dai H, Hart AA, Voskuil DW, Schreiber GJ, Peterse JL, Roberts C, Marton MJ, Parrish M, Atsma D, Witteveen A, Glas A, Delahaye L, van der Velde T, Bartelink H, Rodenhuis S, Rutgers ET, Friend SH, Bernards R (2002) A gene-expression signature as a predictor of survival in breast cancer. N Engl J Med 347:1999-2009

15. Bueno-de-Mesquita JM, van Harten WH, Retel VP, van't Veer LJ, van Dam FS, Karsenberg K, Douma KF, van Tinteren H, Peterse JL, Wesseling J, Wu TS, Atsma D, Rutgers EJ, Brink G, Floore AN, Glas AM, Roumen RM, Bellot FE, van Krimpen C, Rodenhuis S, van de Vijver MJ, Linn SC (2007) Use of 70-gene signature to predict prognosis of patients with node-negative breast cancer: a prospective community-based feasibility study (RASTER). Lancet Oncol 8:1079-1087

16. Drukker CA, Bueno-de-Mesquita JM, Retel VP, van Harten WH, van Tinteren H, Wesseling J, Roumen RM, Knauer M, van't Veer LJ, Sonke GS, Rutgers EJ, van de Vijver MJ, Linn SC (2013) A prospective evaluation of a breast cancer prognosis signature in the observational RASTER study. Int J Cancer 133:929-936

17. Todd JH, Dowle C, Williams MR, Elston CW, Ellis IO, Hinton CP, Blamey RW, Haybittle JL (1987) Confirmation of a prognostic index in primary breast cancer. Br J Cancer 56:489-492 
18. Drukker CA, van den Hout HC, Sonke GS, Brain E, Bonnefoi H, Cardoso F, Goldhirsch A, Harbeck N, Honkoop AH, Koornstra RH, van Laarhoven HWM, Portielje JEA, Schneeweiss A, Smorenburg CH, Stouthard J, Linn SC, Schmidt MK (2014) Risk estimations and treatment decisions in early stage breast cancer; agreement among oncologists and the impact of the 70-gene signature. Eur J Cancer 50(6):1045-1054

19. Hudis CA, Barlow WE, Costantino JP, Gray RJ, Pritchard KI, Chapman JA, Sparano JA, Hunsberger S, Enos RA, Gelber RD, Zujewski JA (2007) Proposal for standardized definitions for efficacy end points in adjuvant breast cancer trials: the STEEP system. J Clin Oncol 25:2127-2132
20. Bueno-de-Mesquita JM, Nuyten DS, Wesseling J, van Tinteren H, Linn SC, van de Vijver MJ (2010) The impact of interobserver variation in pathological assessment of node-negative breast cancer on clinical risk assessment and patient selection for adjuvant systemic treatment. Ann Oncol 21:40-47 